\title{
PENGARUH WOM, KUALITAS JASA, DAN HARGA TERHADAP KEPUTUSAN PEMBELIAN PAKET TOUR PT BOLAEMAS SUMATERA TRAVEL
}

\author{
Purnama Yanti Purba ${ }^{1}$ \\ Alicia Utari ${ }^{2}$ \\ Devin $^{3}$ \\ Riky $^{4}$ \\ Stephannie $^{5}$
}

Fakultas Ekonomi Universitas Prima Indonesia (UNPRI), Medan, Indonesia email : aliciautariii@gmail.com

\begin{abstract}
ABSTRAK
Pengkajian bermaksud untuk menganalisis pengaruh WOM, kualitas jasa, dan harga terhadap keputusan pembelian paket tour PT Bola Emas Sumatera Travel di kota Medan. Fenomena peningkatan jumlah komplain pelanggan pada tahun 2019, tingginya harga paket tour dibandingkan dengan pesaing, dan tidak tercapainya target penjualan selama beberapa bulan melatarbelakangi penelitian. Simple random sampling digunakan sebagai metode untuk mengambil sampel. Sample yang digunakan berjumlah 188 responden. Metode analisis data digunakan regresi linear berganda. Hasilnya yaitu adalah WOM dan kualitas jasa tidak mempunyai pengaruh yang positif secara parsial dan signifikan terhadap keputusan pembelian paket tour PT Bola Emas Sumatera Travel. Harga mempunyai pengaruh yang negatif secara parsial dan signifikan terhadap keputusan pembelian paket tour PT Bola Emas Sumatera Travel. WOM, kualitas jasa, dan harga mempunyai pengaruh yang positif secara simultan terhadap keputusan pembelian paket tour PT Bola Emas Sumatera Travel.
\end{abstract}

Kata kunci : WOM; kualitas jasa; harga; keputusan pembelian

\begin{abstract}
This research purpose is to analyze the effect of WOM, service equality, and price on purchasing decision of tour packages at PT Bola Emas Sumatera Travel in Medan. The phenomenon of increasing number of customer complaints in 2019, higher price of tour packages compared to competitors, and not achieving sales targets for several months are the background of research. Sampling method used was simple random sampling. Samples taken were 188 respondents. Analysis data method used is multiple linear regression analysis. The results show WOM and service quality partially don't have positive effect partially and significant on purchasing decision of tour packages at PT Bola Emas Sumatera Travel. Price has negative effect partially and significant on purchasing decision of tour packages at PT Bola Emas Sumatra Travel. WOM, service equality, and price simultaneously have positive effect on the decision of purchasing tour packages at PT Bola Emas Sumatra Travel.

Keywords : WOM; service equality; price; purchase decision
\end{abstract}




\section{PENDAHULUAN}

Indonesia, perkembangan pariwisata mengalami kemajuan yang semakin pesat, dilihat dari inovasi dan penawarannya. Pariwisata didapuk sebagai sektor ekonomi terpenting sejak 2009. Hal ini menyebabkan pariwisata berada di urutan ke-3 penerimaan devisa terbanyak setelah komoditas minyak, gas bumi dan minyak kelapa sawit (Wibowo \& Donni, 2017). Para konsumen dihadapkan dengan beragam macam tawaran yang datang bukan hanya saja dari lingkungan sekitar, tetapi juga dari e-commerce. Perkembangan digital didukung oleh dunia komunikasi yang semakin lama semakin modern memberikan kemudahan kepada konsumen dalam menentukan keputusan (Manengal, 2015). Dewasa ini, permintaan masyarakat akan jasa industri pariwisata semakin meningkat. Hal ini menyebabkan bisnis travel agent sangat mudah ditemukan diberbagai pelosok daerah. Pelaku bisnis jasa yang bertambah dan berkembang terus menjadikan tantangan tersendiri untuk menciptakan diferensiasi yang unik (Limakrisna \& Susilo, 2012).

Dewasa ini, permintaan masyarakat Medan akan jasa industri pariwisata semakin meningkat. Hal ini menyebabkan bisnis travel agent sangat mudah ditemukan diberbagai tempat mulai dari ditengah kota hingga pelosok daerah. Bisnis ini menawarkan jasa mulai dari pembuatan passport, pembuatan visa berbagai negara, pembelian tiket pesawat dan hotel di seluruh dunia serta yang paling di incar oleh konsumen adalah Paket Tour. Banyaknya bisnis industri perjalanan yang bermunculan saat ini dikarenakan kebutuhan masyarakat akan jasa ini semakin meningkat (Alma, 2018).

Semakin berkembang dan bertambahnya pelaku bisnis dibidang ini, maka semakin membuat para pelakunya ditantang untuk dapat menciptakan diferensiasi yang unik sehingga konsumen dapat membedakan dengan para pesaingnya. Dalam menghadapi lingkungan persaingan yang semakin lama semakin ketat, setiap perusahaan dituntut harus mengoptimalkan semua penawaran yang akan di tawarkan kepada konsumen guna meningkatkan daya saing di pasar serta perusahaan juga dituntut untuk mampu meramu serangkaian strategi pemasaran yang efektif dan mengembangkan strategi pemasaran tersebut secara terusmenerus agar dapat berkelanjutan. Daya saing di bidang industri perjalanan yang sangat ketat dan tinggi ini juga perlu didukung oleh optimalisasi berbagai faktor pendukung guna menunjang berkembangnya pangsa pasar perusahaan (Abdurahhman, 2015).

Untuk mendapatkan keputusan pembelian yang baik dan terus berkelanjutan maka perusahaan harus memperhatikan penetapan harga yang merupakan hal pertama yang diperhatikan konsumen. Seberapa loyal seorang konsumen, jika harga dianggap kurang dapat bersaing dan produk yang ditawarkan sama dengan yang lain, maka konsumen tersebut dapat merubah keputusannya dan berpaling dari perusahaan. Sudah banyak sekali perusahaan travel konvensional yang berhadapan dengan konsekuensi yang paling berat yaitu kehilangan konsumennya akibat harga yang tidak kompetitif. Diantara lingkungan persaingan travel agent di Kota Medan, masing-masing perusahaan berlomba-lomba menawarkan jasa dengan harga yang sangat kompetitif. Untuk itu, para konsumen semakin terbuka peluangnya untuk berpaling dari travel agent pilihannya karena banyak sekali 
pilihan lainnya yang dapat dipilih. Apalagi travel konvensional dewasa ini dihadapkan dengan persaingan yang sangat berat yang mampu menggeser posisinya di mata konsumen, yaitu keberadaan Online Travel Agents. Harga yang ditawarkan juga terkadang jauh lebih murah dan sering didampingi dengan promo yang sangat menggiurkan (Lubis, 2017). Hal ini tentu saja merupakan ancaman bagi perusahaan travel konvensional (Kotler \& Ketler, 2009).

Kemajuan di era globalisasi saat ini, tidak hanya industri manufaktur saja yang mendominasi aktivitas perekonomian di seluruh dunia, namun industri jasa turut juga memegang peranan cukup penting. Hal ini tentu saja akan menyebabkan persaingan yang ketat diantara perusahaan sejenis tersebut. Terutama dalam hal memperoleh dan mempertahankan pelanggan. Strategi dan kebijakan dalam bisnis sangatlah diperlukan dalam persaingan usaha. Hal ini diperlukan perusahaan yang dituntut harus memiliki keunggulan kompetitif sehingga perusahaan memiliki nilai lebih dibanding dengan pesaingnya. Kemampuan dan keunggulan perusahaan harus dipergunakan secara tepat, sehingga dapat menjadi sebuah keunggulan dalam memajukan bisnis perusahaan. Khususnya pada perusahaan jasa. Perusahaan jasa harus memiliki strategi khusus yang baik karena produk yang diberikan berbentuk layanan jasa, sehingga perusahaan dapat menjadi unggul dengan memberikan pelayanan yang lebih agar konsumen merasa nyaman dan percaya akan layanan jasa yang diberikan.

Penduduk di Indonesia mempunyai pola kebutuhan serta pembelian pada setiap rumah tangga yang berbeda-beda, karena setiap rumah tangga memiliki jenis pengeluaran yang bermacam-macam dari kebutuhan yang sifatnya primer, sekunder dan tersier. Jenis pengeluaran yang bermacam-macam itulah yang akhirnya membentuk suatu gaya hidup setiap rumah tangga menjadi berbeda-beda dan hal tersebut yang menjadikan alasan mengapa presentase dari pendapatan suatu rumah tangga untuk setiap jenis pengeluaran rumah tangga itu berbedabeda, misalnya rumah tangga yang kebutuhan primer dan sekundernya telah terpenuhi secara optimal, maka akan beranjak ke kebutuhan selanjutnya yaitu kebutuhan tersier (Pamungkas, 2016).

Dengan adanya bisnis jasa travel agent yang semakin banyak, konsumen menjadi selalu membanding-bandingkan perbedaan yang satu dengan yang lainnya. Setiap pelaku usaha dituntut untuk terus mengoptimalkan semua penawaran semaksimal mungkin agar dapat meningkatkan daya saing disaat menghadapi persaingan yang teramat ketat (Lubis, 2017). Disamping itu, perusahaan harus terus menciptakan serangkaian strategi pemasaran yang jitu agar dapat menciptakan perbedaan dengan pesaingnya. Daya saing di bidang industri perjalanan yang sangat ketat dan tinggi ini juga perlu didukung oleh optimalisasi berbagai faktor pendukung guna menunjang berkembangnya pangsa pasar perusahaan (Manengal, 2015).

Konsumen membuat keputusan pembelian hampir setiap saat dan sebagian perusahaan selalu memantau pergerakan konsumennya agar selalu dipertimbangkan saat konsumen tersebut ingin membeli produk apa, bagaimana dan berapa banyak serta kapan dan alasan mengapa produk akan dibeli. Pelaku usaha harus belajar secara nyata mengenai hal-hal penting yang konsumen lakukan sebelum melakukan suatu transaksi (Tjiptono \& Diana, 2016). 
Word of mouth merupakan suatu bentuk promosi yang berupa rekomendasi dari mulut ke mulut tentang kebaikan dalam suatu produk. Pemasaran dari mulut ke mulut ini merupakan pemasaran yang simple, tidak membutuhkan biaya besar namun efektifitasnya sangat besar. Komunikasi yang komunikatif sangat dibutuhkan dalam membangun suatu relasi yang baik antar individu dalam keluarga dan masyarakat. Demikian halnya dalam setiap usaha, bahwa komunikasi merupakan hal yang amat penting sebagai sarana efektif dalam memajukan dan mengembangkan usaha yang bersangkutan. Komunikasi dari mulut ke mulut merupakan salah satu saluran komunikasi yang sering digunakan oleh perusahaan yang memproduksi baik barang maupun jasa karena komunikasi dari mulut ke mulut (word of mouth) dinilai sangat efektif dalam memperlancar proses pemasaran dan mampu memberikan keuntungan kepada perusahaan (Malau, 2016).

Kualitas jasa merupakan suatu kondisi dinamis yang berhubungan dengan produk, jasa, manusia, proses dan lingkungan yang memenuhi atau melebihi harapan. Layanan dalam hal ini berupa kemudahan, kecepatan, hubungan, kemampuan dan keramahtamahan yang ditujukan melalui sikap dan sifat dalam memberikan layanan untuk kepuasan konsumen. Konsumen yang merasa puas dengan kualitas jasa cenderung lebih memilih memakai jasa dari travel tersebut serta akan memberikan rekomendasi kepada orang lain untuk membeli di tempat yang sama dan sebaliknya apabila konsumen merasa tidak puas dengan kualitas jasa maka konsumen akan beralih ke travel lain (Lubis, 2017).

Harga merupakan satu-satunya dari unsur bauran pemasaran yang bisa mendatangkan pendapatan bagi perusahaan. Harga sifatnya fleksibel dimana setiap saat dapat berubah dengan sendirinya. Harga merupakan label yang ada dalam sebuah produk yang harus dibayar agar bisa mendapatkan produk atau jasa. Harga merupakan faktor yang berpengeraruh signifikan pada keputusan pembelian. Pelanggan sering melakukan perbandingan harga produk sebelum melakukan pembelian (Wibowo \& Donni, 2017).

PT Bola Emas Sumatera Travel merupakan perusahaan yang bergerak dibidang industri perjalanan dan menawarkan berbagai jasa seperti pembuatan passport, visa negara asing, tiket pesawat dan hotel diseluruh pelosok dunia dan paket tour baik inbound/domestic dan outbound/internasional. Perkembangan jasa pariwisata semakin pesat di Kota Medan merupakan tujuan didirikannya PT Bola Emas Sumatera Travel. Selain itu juga dikarenakan minat masyarakat yang tinggi untuk memenuhi kebutuhan jasa khususnya perjalanan wisata. PT Bola Emas Sumatera Travel atau Best Holiday adalah salah satu travel agent terpercaya di Kota Medan sejak tahun 1990 sampai sekarang.

PT Bola Emas Sumatera Travel memiliki komitmen yaitu selalu mengutamakan pelayanan yang terbaik sesuai dengan kebutuhan jasa pariwisata dan hal tersebutlah yang menjadi keunggulan perusahaan. 'One-stop Travel Solution" adalah corporate value yang terus dijaga selama bertahun-tahun. Informasi yang lengkap mengenai jasa wisata pariwisata dalam / luar negeri adalah jaminan pelayanan perusahaan. 
Tabel 1.

Rekapitulasi Data Penjualan PT. Bola Emas Sumatera Travel Bulan Juni 2018-Juni 2019

\begin{tabular}{lllrr}
\hline Tahun & Bulan & $\begin{array}{c}\text { Target } \\
\text { Perusahaan } \\
\text { (Rupiah) }\end{array}$ & $\begin{array}{c}\text { Reliasi } \\
\text { Perusahaan } \\
\text { (rupiah) }\end{array}$ & $\begin{array}{c}\text { Persentase } \\
\text { \% }\end{array}$ \\
\hline 2018 & Juni & 5.000 .000 .000 & 3.172 .300 .000 & 63 \\
& Juli & 5.000 .000 .000 & 3.712 .300 .000 & 74 \\
& Agustus & 5.000 .000 .000 & 4.915 .100 .000 & 98 \\
& September & 5.000 .000 .000 & 5.3 .51 .700 .000 & 107 \\
& Oktober & 5.000 .000 .000 & 5.878 .100 .000 & 118 \\
& November & 5.000 .000 .000 & 5.419 .700 .000 & 108 \\
& Desember & 5.000 .000 .000 & 5.469 .200 .000 & 109 \\
\hline 2019 & Januari & 5.000 .000 .000 & 3.866 .000 .000 & 77 \\
& Februari & 5.000 .000 .000 & 3.702 .300 .000 & 74 \\
& Maret & 5.000 .000 .000 & 5.393 .000 .000 & 108 \\
& April & 5.000 .000 .000 & 5.987 .800 .000 & 120 \\
& Mei & 5.000 .000 .000 & 5.939 .000 .000 & 119 \\
& Juni & 5.000 .000 .000 & 5.356 .000 .000 & 107 \\
\hline & Total & 60.000 .000 .000 & 64.162 .500 .000 & 107 \\
\hline
\end{tabular}

Sumber : PT Bola Emas Sumatera Travel, (2020)

Tabel 1. terlihat bahwa bahwa realisasi penjualan paket tour tidak tercapai pada bulan Juni'18, Juli'18, Agustus'18, Januari'19 dan Februari'19. Peningkatan jumlah komplain pelanggan, tingginya harga paket tour dibandingkan dengan pesaing, dan tidak tercapainya target penjualan selama beberapa bulan melatarbelakangi penelitian ini. Untuk mendapatkan keputusan pembelian yang baik dan terus berkelanjutan maka perusahaan harus memperhatikan penetapan harga yang merupakan hal pertama yang diperhatikan konsumen. Seberapa loyal seorang konsumen, jika harga dianggap kurang dapat bersaing dan produk yang ditawarkan sama dengan yang lain, maka konsumen tersebut dapat merubah keputusannya dan berpaling dari perusahaan (Malau, 2016).

Sudah banyak sekali perusahaan travel konvensional yang berhadapan dengan konsekuensi yang paling berat yaitu kehilangan konsumennya akibat harga yang tidak kompetitif (Shimp, 2014). Diantara lingkungan persaingan travel agent di Kota Medan, masing-masing perusahaan berlomba-lomba menawarkan jasa dengan harga yang sangat kompetitif. Untuk itu, para konsumen semakin terbuka peluangnya untuk berpaling dari travel agent pilihannya karena banyaknya pilihan (Lubis, 2017). Terutama travel konvensional dewasa ini dihadapkan dengan persaingan yang sangat berat yang mampu menggeser posisinya di mata konsumen, yaitu keberadaan Online Travel Agents (Rusdiana, 2014). Harga yang ditawarkan juga terkadang jauh lebih murah dan sering didampingi dengan promo yang sangat menggiurkan. Inilah yang menjadi ancaman dan tantangan tersendiri bagi perusahaan travel yang masih konvensional (Sutisna, 2012).

Salah satu bentuk promosi dengan cara rekomendasi mulut langsung ke mulut konsumen yang memiliki tujuan untuk memberitakan informasi yang berupa kebaikan produk dan jasa merupakan Word of Mouth (WOM (Kotler \& Ketler, 2009)). WOM berarti pemasaran simple dan tidak melibatkan biaya besar 
serta memiliki efektifitas yang maksimal. Dalam membangun relasi dibutuhkan komunikasi yang komunikatif terutama antara keluarga dan lingkungan masyarakat. Dalam setiap usaha, komunikasi selalu menjadi hal terpenting dan sebagai sarana yang efektif guna mengembangkan dan memajukan usaha. Sebagai sarana komunikasi yang paling sering digunakan baik bidang jasa maupun produk, WOM dinilai paling bagus dalam memperlancar proses pemasaran serta mampu mendorong keuntungan perusahaan (Sangadji et al., 2013).

Kondisi yang dinamis dimana memiliki hubungan dengan orang, suatu proses, jasa dan cakupan lingkungan untuk melebihi atau memenuhi harapan disebut kualitas jasa (Sunyoto, 2014). Layanan yang dimaksud yaitu kecepatan, kemudahan, kemampuan, keramah-tamahan dan hubungan yang ditujukan melalui sikap dan sifat memberi layanan dengan tujuan memenuhi kepuasan konsumen. Konsumen yang merasakan kepuasan dengan kualitas jasa yang diberikan akan cenderung lebih memilih memakai kembali jasa dari travel tersebut serta kemungkinan akan memberikan rekomen ke orang lain agar melakukan transaksi dan mencoba. Begitu juga kebalikannya, apabila konsumen tidak puas dengan kualitas jasa, konsumen akan beralih ke travel lain (Tjiptono, 2012).

Salah satu unsur dari bauran di pemasaran dimana bertujuan mendatangkan profit untuk perusahaan adalah dari terbentuknya harga. Harga bersifat fleksibel dan dapat berubah-ubah dengan sendiri (Wibowo, 2016). Harga selalu menjadi patokan sebuah produk yang menjadi label untuk mendapatkan produk atau jasa. Disamping itu, faktor yang dipercaya dapat mempengaruhi keputusan dalam pembelian yaitu harga. Konsumen akan terus membandingkan harga dengan pesaing sebelum membuat suatu pembelian (Wibowo, 2016).

Keputusan pembelian adalah suatu purchase-decision yang dibuat konsumen dalam membuat transaksi merek yang diminati, dan melibatkan 2 faktor yaitu antara taat dalam bertransaksi dan keputusan dalam melakukan pembelian (Kotler \& Gary Amstrong, 2018) .

WOM adalah sebuah pujian atau rekomen dari komentar seorang konsumen disekitar pengalaman yang dialami mereka terhadap layanan produk dan jasa dimana dinilai mempengaruhi keputusan konsumen atau perilaku dalam pembelian (Ginting \& Hartimbul, 2017). Kualitas jasa terdapat 2 faktor utama yaitu expected service (jasa yang diharapkan) dan perceived service (jasa yang dipersepsikan). Dengan fokus terhadap pemenuhan kebutuhan sekaligus keinginan pelanggan serta ketepatan penyampaian layanan untuk sesuai dengan harapan pelanggan. (Tjiptono, 2012).

Harga menurut Assauri (2014) adalah unsur tunggal marketing mix yang dapat menghasilkan penerimaan dan pendapatan penjualan sehingga unsur lain hanyalah unsur biaya.

Penelitian sebelumnya yang dilaksanakan oleh Assauri (2014) menyatakan kualitas jasa dan harga mempunyai pengaruh yang positif terhadap keputusan dalam pembelian karena pelanggan sangat mengutamakan kualitas layanan yang akan diterima dan didukung oleh harga terjangkau dan dapat bersaing. Pamungkas (2016) dalam penelitiannya WOM berpengaruh terhadap keputusan pembelian jika ditawarkan langsung dari mulut ke mulut, pelanggan menjadi lebih paham 
terutama yang berasal dari konsumen yang sudah merasakan langsung jasa yang ditawarkan.

$\mathrm{H}_{1}$ : WOM berpengaruh signifikan dan positif terhadap keputusan pembelian.

WOM menurut Alma (2018) adalah memberi seseorang alasan agar membincangkan mengenai produk ataupun jasa dan untuk memudahkan ketika pembicaraan terjadi. Kesimpulan yang dapat dikutip dari pendapat ahli bahwa WOM menghasilkan percakapan yang baik. Sesaat sebelum diputuskan untuk bertransaksi atau tidak, konsumen terus mengali informasi dahulu tentang kualitas barang atau jasa. Informasi tersebut didapat dari rekan dekat seperti keluarga dan teman/sahabat yang sudah pernah berhubungan langsung dengan perusahaan. Setelah memperoleh informasi, konsumen baru akan mempertimbangkan akan melakukan transaksi atau tidak diperusahaan tersebut.

$\mathrm{H}_{2}$ : Kualitas jasa berpengaruh signifikan dan positif terhadap keputusan pembelian.

Kualitas jasa menurut Damiati (2017) adalah perbedaan yang jauh antara 2 hal yaitu realitas dan persepsi pelanggan dari layanan yang akan diterima atau diperoleh. Kesimpulan yang dapat dikutip dari pendapat ahli bahwa kualitas jasa adalah faktor yang selalu diperhatikan konsumen sebelum menetapkan keputusan pembelian. Selama proses bisnis baik bidang produk ataupun jasa, konsumen selalu menuntut untuk mendapatkan pelayanan yang baik dikarenakan adanya hubungan erat antara kualitas jasa dan keputusan pembelian. Agar dapat mempetahankan bisnisnya, pelaku usaha harus bisa bersaing dengan baik dengan terus menjaga kualitas jasa dan meminimkan adanya rasa kecewa dari konsumen.

$\mathrm{H}_{3}$ : Harga berpengaruh signifikan dan positif terhadap keputusan pembelian.

Harga yaitu sejumlah biaya/uang yang dibayarkan oleh pelanggan demi memperoleh sesuatu yang diinginkan. Kesimpulan yang dapat dikutip dari pendapat ahli bahwa harga merupakan indikator nilai yang penting bila dihubungkan dengan manfaat yang dirasakan (Kotler \& Gary Amstrong, 2018). Faktor yang memiliki kaitan dengan harga menjadi latar belakang alasan pembeli setuju melakukan transaksi dikarenakan pembeli tersebut memiliki rasa penasaran dan ingin merasakan langsung manfaat dari jasa tersebut. Tentunya didukung oleh harga yang terjangkau dan budget konsumen (Abdurahhman, 2015). Harga seringkali menjadi suatu pertimbangan paling utama untuk mengambil keputusan untuk bertransaksi, karena harga merupakan sesuatu yang seharusnya dikeluarkan konsumen demi mencapai keinginan untuk mendapat suatu barang atau jasa.

$\mathrm{H}_{4}$ : WOM, kualitas jasa, dan harga berpengaruh signifikan dan positif terhadap keputusan pembelian.

\section{METODE PENELITIAN}

Objek penelitian adalah PT Bola Emas Sumatera Travel. Terletak di Kota Medan, tepatnya beralamat di Jalan Kejaksaan No.180/P-4, Medan Petisah. Terletak di jantung kota Medan membuat PT Bola Emas Sumatera Travel menjadi tempat yang strategis dibandingkan pesaingnya. Waktu penelitian selama bulan April 2019 sampai dengan April 2020. Pendekatan penelitian menggunakan penelitian kuantitatif, yang berarti penelitian dimana terdiri dari angka dan 
dianalisis dengan statistik agar dapat mengukur dan mendapatkan hasil dari penelitian (Sugiyono, 2017).

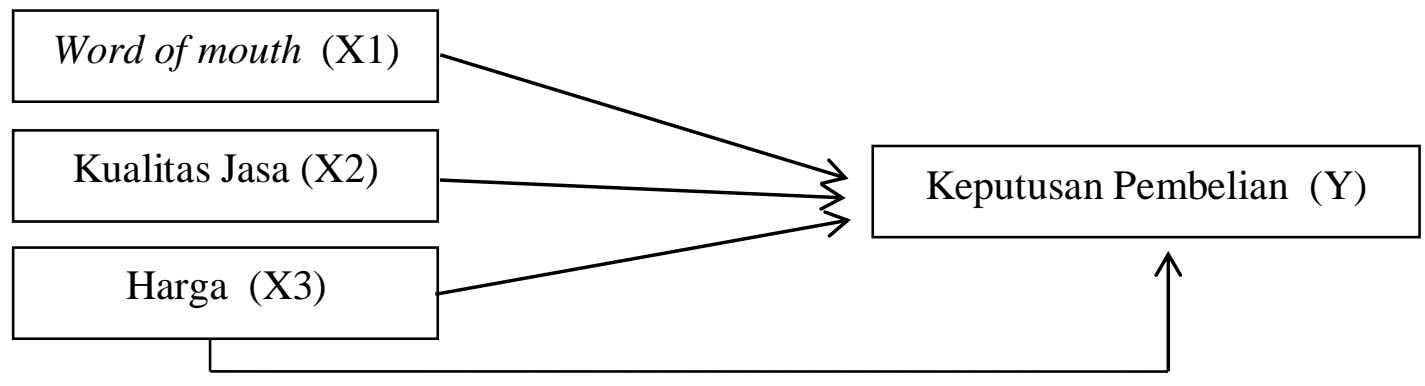

Gambar 1. Model Kerangka Konseptual

Skala ukuran data merupakan suatu perangkat aturan yang dibutuhkan untuk "mengkuantitatif" data dalam mengukur suatu variabel. Skala ukuran yang digunakan adalah skala likert yaitu rentang 1 - 5 yang diberikan skor yaitu jawaban SS = Sangat Setuju (5), S = Setuju (4), KS = Kurang Setuju (3), TS = Tidak Setuju (2), dan STS = Sangat Tidak Setuju (1). Penganalisis data dibantu oleh program dari komputer berupa SPSS.

Tabel 2.

Variabel \& Indikator Penelitian

\begin{tabular}{|c|c|c|}
\hline Variabel & Indikator & Sumber \\
\hline $\begin{array}{l}\text { Word of mouth } \\
\qquad\left(\mathrm{X}_{1}\right)\end{array}$ & $\begin{array}{l}\text { 1. Intensity } \\
\text { 2. Positive Valence } \\
\text { 3. Negative Valence } \\
\text { 4. Content }\end{array}$ & $\begin{array}{c}\text { Goyette et al } \\
(2016: 150)\end{array}$ \\
\hline $\begin{array}{l}\text { Kualitas Jasa } \\
\qquad\left(\mathrm{X}_{2}\right)\end{array}$ & $\begin{array}{l}\text { 1. Professionalism \& Skills } \\
\text { 2. Attitudes \& Behavior } \\
\text { 3. Accessbility \& Flexibility } \\
\text { 4. Realibility \& Trustworthiness } \\
\text { 5. Recovery }\end{array}$ & $\begin{array}{c}\text { Tjiptono } \\
(2017: 276)\end{array}$ \\
\hline $\begin{array}{l}\text { Harga } \\
\left(\mathrm{X}_{3}\right)\end{array}$ & $\begin{array}{l}\text { 1. Harga sesuai dengan manfaat } \\
\text { 2. Persepsi harga \& manfaat } \\
\text { 3. Harga barang terjangkau } \\
\text { 4. Persaingan harga } \\
\text { 5. Kesesuaian harga }\end{array}$ & Fure (2013:276) \\
\hline $\begin{array}{l}\text { Keputusan Pembelian } \\
\text { (Y) }\end{array}$ & $\begin{array}{l}\text { 1. Pengenalan masalah } \\
\text { 2. Penelitian informasi } \\
\text { 3. Pengevaluasian alternatif } \\
\text { 4. Keputusan pembelian } \\
\text { 5. Perilaku Pasca Pembelian }\end{array}$ & $\begin{array}{c}\text { Assauri } \\
(2014: 140)\end{array}$ \\
\hline
\end{tabular}

Sumber: Data primer yang diolah, 2019

Jenis dari penelitian menggunakan deskriptif kuantitatif dan bersifat descriptive explanatory. Pelanggan yang membeli paket tour pada PT Bola Emas Sumatera Travel dari bulan Januari - April 2020 sebanyak 356 orang 
adalah populasi. Simple random sampling adalah teknik yang digunakan untuk pengambilan sample. Metode analisis regresi linear berganda adalah metode penganalisis data yang digunakan di penelitian ini. Total sampel yaitu sebanyak 188 orang yang membeli paket tour pada PT Bola Emas Sumatera Travel. Teknik pengumpulan data menggunakan pengisian kuisioner. Sumbersumber data penelitian yang dikumpulkan adalah data primer yang didapatkan dari olahan data di SPSS dan data sekunder yang didapatkan dari perusahaan (Sugiyono, 2017).

\section{HASIL DAN PEMBAHASAN}

PT Bola Emas Sumatera Travel merupakan sebuah perusahaan yang bergerak dibidang jasa perjalanan yang meliputi perjalanan udara,darat dan laut. PT Bola Emas Sumatera Travel merupakan perusahaan jasa parawisata yang meliputi Tours dan Travel, penjualan tiket pesawat, perjalanan wisata dalam dan luar negeri, Hotel Reservation, dan lain-lain. Lokasi perusahaan di Jalan Kejaksaan No 180 P/4 Medan. Perkembangan dunia usaha yang semakin pesat di Medan merupakan dasar didirikannya PT Bola Emas Sumatera Travel dinilai tingginya minat masyarakat dalam memenuhi kebutuhan akan sarana transportasi khususnya untuk perjalanan wisata.

PT Bola Emas Sumatera Travel atau Best Holiday adalah salah satu travel agent terpercaya di Kota Medan yang telah berdiri sejak tahun 1990. Bermula hanya dengan melayani ticketing untuk corporate clients seperti Siemens, PT Socfindo dan ekspatriat mancanegara. Kini, PT Bola Emas Sumatera Travel telah bertransformasi menjadi one-stop travel solution bagi pelanggan korporasi dan individu dengan spesialisasi layanan leisure tours, corporate travel dan corporate meeting, incentive, convention \& exhibition (MICE). PT Bola Emas Sumatera Travel ini didirikan oleh bapak Tjen San Erwin. Dengan dukungan oleh team yang berpengalaman dan propesional, diyakini dapat memberi solusi terhadap seluruh kebutuhan klien dari berbagai skala dan segmen. Terbukti dengan lebih dari 1500 klien individu dan klien korporat seperti PT Adira Multi Finance Tbk., PT Union Confectionery, PT Growth Sumatra, PT Socfindo, Wiraland Property Group dan masih banyak lainnya yang telah mempercayakan PT Bola Emas Sumatera Travel untuk mengelola kebutuhan business \& leisure trip mereka hingga saat ini. PT Bola Emas Sumatera Travel berkomitmen mengutamakan pelayanan terbaik sesuai dengan kebutuhan jasa parawisata yang menjadi unggulan perusahaan. Karena melalui company profil tersebut mereka siap menjadi 'One-stop Travel Solution". Kelengkapan informasi menjadi jaminan pelayanan kami dalam seluruh bidang jasa wisata pariwisata dalam / luar negeri.

Pengisian kuesioner adalah instrument yang digunakan penelitian ini. Total semua pertanyaan kuisioner yaitu sebanyak 38 pertanyaan berupa 8 pertanyaan untuk variabel WOM $\left(\mathrm{X}_{1}\right), 10$ pertanyaan untuk variabel kualitas jasa $\left(\mathrm{X}_{2}\right), 10$ pertanyaan untuk variabel harga $\left(\mathrm{X}_{3}\right)$, dan 10 pertanyaan untuk variabel keputusan dari pembelian paket tour $(\mathrm{Y})$. 
Tabel 3.

Karakteristik Responden PT Bola Emas Sumatera Travel

\begin{tabular}{|c|c|c|c|}
\hline No. & Karakteristik Responden & Jumlah (Orang) & $\begin{array}{c}\text { Persentase } \\
(\%)\end{array}$ \\
\hline \multirow[t]{7}{*}{1.} & Umur & & \\
\hline & Berumur $<20$ & 8 & 4 \\
\hline & b. Berumur 20-30 & 45 & 24 \\
\hline & c. Berumur $31-40$ & 50 & 27 \\
\hline & d. Berumur 41-50 & 55 & 29 \\
\hline & e. $\quad$ Berumur $>50$ & 30 & 16 \\
\hline & Total & 188 & 100 \\
\hline \multirow[t]{6}{*}{2.} & Tingkat Pendidikan & & \\
\hline & a. Jenjang SLTA & 50 & 27 \\
\hline & b. Jenjang D3 & 30 & 16 \\
\hline & c. Jenjang S1 & 100 & 53 \\
\hline & d. Jenjang S2 & 8 & 4 \\
\hline & Total & 188 & 100 \\
\hline \multirow[t]{4}{*}{3.} & Gender (Jenis Kelamin) & & \\
\hline & a. Gender Pria & 95 & 51 \\
\hline & b. Gender Wanita & 93 & 49 \\
\hline & Total & 188 & 100 \\
\hline \multirow[t]{6}{*}{4.} & Frekuensi Pembelian dalam 1 tahun & & \\
\hline & a. Frekuensi 1-5x & 100 & 53 \\
\hline & b. Frekuensi 6-10x & 50 & 27 \\
\hline & c. Frekuensi $11-15 x$ & 30 & 16 \\
\hline & d. Frekuensi >15x & 8 & 4 \\
\hline & Total & 188 & 100 \\
\hline
\end{tabular}

Sumber: Data primer yang diolah, 2020

Sebanyak 188 responden berpartisipasi dalam pengisian kuisioner. Kuesioner yang berisikan pertanyaan-pertanyaan mengenai WOM, kualitas jasa, harga dan keputusan pembelian bagian paket tour pada PT Bola Emas Sumatera Travel kemudian disebar agar dapat diisi oleh responden. Dari kuisioner tersebut kemudian diperoleh gambaran umum responden perusahaan. Karakteristik yang terkumpul dirangkum dalam 5 jenis yaitu umur, tingkat pendidikan, jenis kelamin, dan frekuensi pembelian dalam 1 tahun. Berikut karakteristik responden PT Bola Emas Sumatera Travel yang didapat melalui kuisioner.

Data diatas menunjukan pelanggan berumurnya paling dominan adalah responden umur 41-50 tahun yaitu berjumlah 55 orang / 29\%. Hal ini disebabkan karena pelanggan PT Bola Emas Sumatera Travel merupakan kalangan orang tua yang membeli paket tour untuk menghabiskan waktu luang dan tidak bergantung kepada musim liburan dan juga karena diperlukan dana yang cukup besar untuk melakukan transaksi paket tour.

Pelanggan yang tingkat pendidikannya paling dominan adalah responden yang tingkat pendidikan jenjang S1 yaitu berjumlah 100 orang / 53\%. Hal ini disebabkan rata-rata pelanggan PT Bola Emas Sumatera Travel merupakan kalangan dari pebisnis dan kebanyakan merupakan tamatan S1. PT Bola Emas Sumatera Travel dikenal baik dikalangan pebisnis dikarenakan adanya relasi yang baik dan pernah adanya keterikatan kontrak dengan perusahaan seperti PT Adira 
Multi Finance Tbk, PT Union Confectionery, PT Growth Sumatra, PT Socfindo, Wiraland Property Group dan lainnya.

Pelanggan yang jenis kelaminnya paling dominan adalah responden bergender laki-laki berjumlah 95 orang / 51\%. Hal ini dikarenakan rata-rata yang memesan paket tour PT Bola Emas Sumatera Travel adalah para pebisnis yang didominasi oleh laki-laki. Diketahui bahwa jumlah pelanggan perempuan yang memesan paket tour hampir sama dengan laki-laki. Hal tersebut dikarenakan pelanggan perempuan banyak melakukan pemesanan paket tour di tahun 2019.

Pelanggan yang frekuensi pembelian dalam 1 tahun paling dominan adalah responden frekuensi pembelian 1-5x yaitu sejumlah 100 orang / 53\%. Hal ini disebabkan kebanyakan pelanggan PT Bola Emas Sumatera Travel melakukan repeat-order hanya 1-5x saja dikarenakan pelanggan tidak selalu menggunakan jasa PT Bola Emas Sumatera Travel setiap liburan. Pelanggan juga mencari para pesaing lainnya dengan memperhatikan beberapa faktor seperti isi perjalanan, tanggal keberangkatan dan harga.

Penelitian di PT Bola Emas Sumatera Travel yaitu variabel bebas (independent variabel) yang diamati terdiri atas WOM $\left(\mathrm{X}_{1}\right)$, kualitas jasa $\left(\mathrm{X}_{2}\right)$, dan harga $\left(\mathrm{X}_{3}\right)$. Variabel terikat (dependent variable) yaitu keputusan pembelian paket tour (Y).

Tabel 4.

Statistik Deskriptif

\begin{tabular}{lrrrrr}
\hline & N & Minimum & Maximum & Mean & $\begin{array}{c}\text { Std. } \\
\text { Deviation }\end{array}$ \\
\hline WOM & 188 & 3,50 & 4,75 & 4,1469 &, 23928 \\
Kualitas Jasa & 188 & 3,00 & 4,80 & 3,7910 &, 41685 \\
Harga & 188 & 3,80 & 4,40 & 3,9702 &, 10376 \\
Keputusan Pembelian Paket & 188 & 3,00 & 5,00 & 3,9133 &, 48780 \\
Tour & 88 & & & & \\
Valid N (listwise) & & & & & \\
Sumber : Data primer yang diolah, 2020 & & & &
\end{tabular}

Data diatas menunjukan mean dari WOM $\left(\mathrm{X}_{1}\right)$ adalah 4,1469 berstandar deviasi 0,23928 dengan nilai min : 3,5 \& nilai max : 4,75. Mean dari kualitas jasa $\left(\mathrm{X}_{2}\right)$ adalah 3,7910 dengan Std. Deviation : 0,41685 dengan nilai min : 3 \& nilai max : 4,80. Mean dari harga $\left(\mathrm{X}_{3}\right)$ adalah 3,9702 dengan Std. Deviation: 0,10376 dengan nilai min : 3,80 \& nilai max : 4,40. Mean dari keputusan pembelian paket tour (Y) adalah 3,9133 dengan Std. Deviation : 0,48780 dengan nilai min : $3 \&$ nilai $\max : 5$.

Uji Validitas yaitu suatu derajat ukur ketepatan untuk mengetahui arti yang sebenarnya dari pengujian instrumen yang digunakan dalam penelitian. Reliabilitas merupakan suatu derajat untuk menguji ketepatan dan keakuratan yang ditunjuk sebagai instrumen untuk pengukuran secara internal untuk menganalisis dan menguji konsistensi pertanyaan yang telah disiapkan.

Tabel 5 membuktikan nilai Corrected item-total correlation WOM $\left(\mathrm{X}_{1}\right)$ adalah diatas $>0,361$, sehingga memiliki nilai validitas yang sangat konsisten. Nilai Corrected item-total correlation variabel kualitas jasa $\left(\mathrm{X}_{2}\right)$ adalah diatas $>$ 0,361 , sehingga memiliki nilai validitas yang sangat konsisten. Nilai corrected 
item-total correlation variabel harga $\left(\mathrm{X}_{3}\right)$ adalah diatas $>0,361$, sehingga memiliki nilai validitas yang sangat konsisten. Nilai corrected item-total correlation variabel keputusan pembelian paket tour (Y) adalah diatas $>0,361$, sehingga memiliki nilai validitas yang sangat konsisten.

Tabel 5.

Rekap Hasil Uji Validitas Instrumen Penelitian

\begin{tabular}{|c|c|c|c|c|}
\hline No. & Variabel & Pertanyaan & $\mathbf{r}_{\text {hitung }}$ & Sig(2-tailed) \\
\hline \multirow[t]{8}{*}{1.} & Word of mouth $\left(\mathrm{X}_{1}\right)$ & $\mathrm{X}_{1.1}$ & 0,506 & 0,004 \\
\hline & & $\mathrm{X}_{1} .2$ & 0,421 & 0,020 \\
\hline & & $\mathrm{X}_{1} .3$ & 0,947 & 0,000 \\
\hline & & $X_{1 .} 4$ & 0,867 & 0,000 \\
\hline & & $X_{1.5}$ & 0,411 & 0,024 \\
\hline & & $X_{1} .6$ & 0,446 & 0,014 \\
\hline & & $\mathrm{X}_{1} .7$ & 0,947 & 0,000 \\
\hline & & $X_{1} .8$ & 0,947 & 0,000 \\
\hline & Kualitas Jasa $\left(\mathrm{X}_{2}\right)$ & $\mathrm{X}_{2 .} .1$ & 0,876 & 0,000 \\
\hline & & $\mathrm{X}_{2} .2$ & 0,859 & 0,000 \\
\hline & & $X_{2} .3$ & 0,523 & 0,003 \\
\hline & & $X_{2 .} 4$ & 0,876 & 0,000 \\
\hline & & $X_{2 .} .5$ & 0,859 & 0,000 \\
\hline & & $X_{2} .6$ & 0,876 & 0,000 \\
\hline & & $X_{2 .} .7$ & 0,859 & 0,000 \\
\hline & & $\mathrm{X}_{2.8}$ & 0,561 & 0,001 \\
\hline & & $\mathrm{X}_{2 .} .9$ & 0,523 & 0,003 \\
\hline & & $\mathrm{X}_{2 .} .10$ & 0,731 & 0,000 \\
\hline & Harga $\left(X_{3}\right)$ & $\mathrm{X}_{3.1}$ & 0,748 & 0,000 \\
\hline & & $X_{3} .2$ & 0,850 & 0,000 \\
\hline & & $X_{3 .} 3$ & 0,748 & 0,000 \\
\hline & & $X_{3.4}$ & 0,850 & 0,000 \\
\hline & & $X_{3} .5$ & 0,850 & 0,000 \\
\hline & & $X_{3} .6$ & 0,850 & 0,000 \\
\hline & & $X_{3.7}$ & 0,850 & 0,000 \\
\hline & & $\mathrm{X}_{3 .} 8$ & 0,760 & 0,027 \\
\hline & & $X_{3 .} 9$ & 0,027 & 0,044 \\
\hline & & $\mathrm{X}_{3 .} 10$ & 0,371 & 0,000 \\
\hline \multirow[t]{10}{*}{4.} & Keputusan Pembelian & $\mathrm{X}_{3.1}$ & 0,748 & 0,000 \\
\hline & $(\mathrm{Y})$ & $X_{3} .2$ & 0,850 & 0,000 \\
\hline & & $X_{3 .} 3$ & 0,748 & 0,000 \\
\hline & & $X_{3 .} 4$ & 0,850 & 0,000 \\
\hline & & $X_{3} .5$ & 0,850 & 0,000 \\
\hline & & $X_{3 .} 6$ & 0,850 & 0,000 \\
\hline & & $X_{3 .} 7$ & 0,850 & 0,000 \\
\hline & & $\mathrm{X}_{3.8} 8$ & 0,760 & 0,027 \\
\hline & & $X_{3.9}$ & 0,027 & 0,044 \\
\hline & & $X_{3} .10$ & 0,371 & 0,000 \\
\hline
\end{tabular}

Sumber: Data primer yang diolah, 2020

Gambar 2. menunjukkan Diagram diatas memperlihatkan balok-balok mengikuti pola garis melengkung membentuk gundulan sehingga diagram historgram menunjukkan distribusi data secara normal. 
Tabel 6.

Tabel Uji Realibilitas

\begin{tabular}{lc}
\hline \multicolumn{1}{c}{ Variabel } & Cronbach's Alpha \\
\hline WOM & 0,851 \\
\hline Kualitas Jasa & 0,918 \\
\hline Harga & 0,857 \\
\hline Keputusan Pembelian & 0,791 \\
\hline
\end{tabular}

Sumber: Data primer yang diolah, 2020

Uji normalitas penelitian ini yaitu menggunakan 2 metode yaitu uji grafik dan statistic. Hasil uji normalitas terlihat pada grafik histrogram dan normal probability plot berikut.

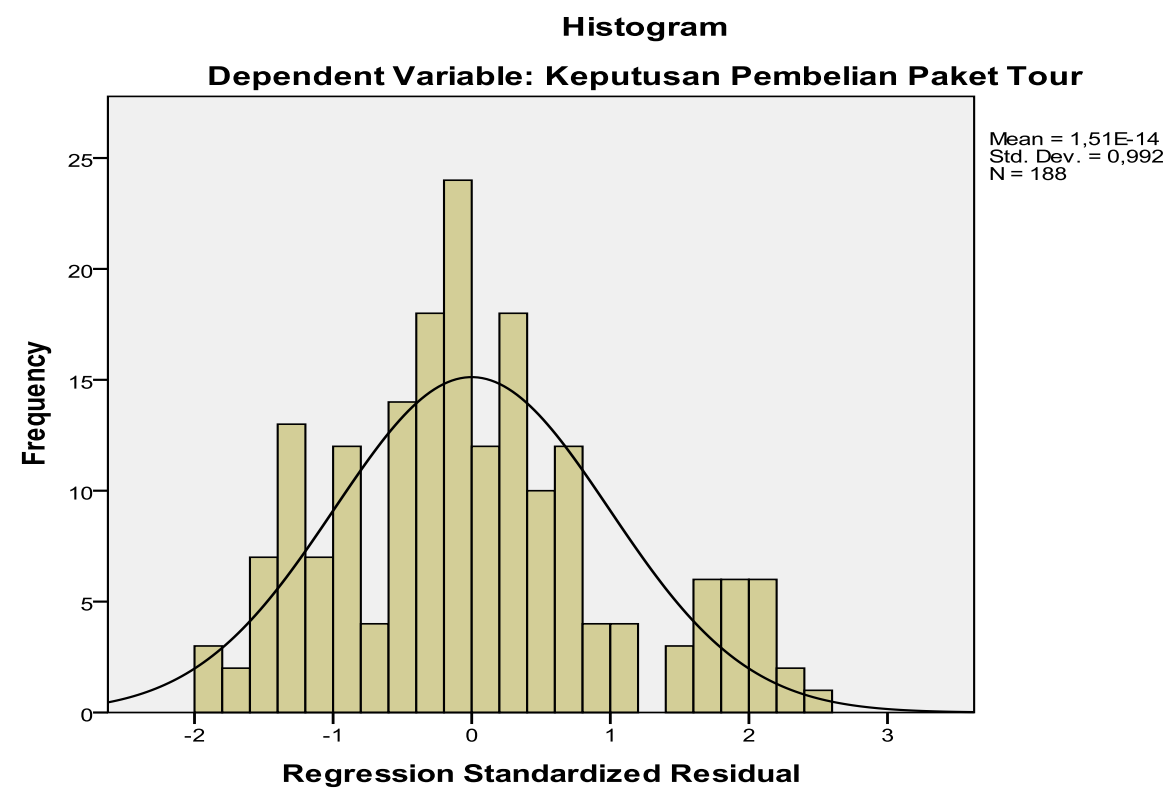

Gambar 2. Histogram

Sumber: Data primer yang diolah, 2020

Gambar 3. memperlihatkan titik penyebaran disekitar garis berdiagonal menyebar mendekat dengan garis berdiagonal lainnya sehingga disimpulkan data dalam model regresi terdistribusi normal.

Tabel 7. memperlihatkan nilai signifikan Kolmogorov-Smirnov (K-S) yaitu sebesar 0,110. Hal ini berarti terdistribusi normal, karena signifikannya $>0.05$ secara statistik.

Data Tabel 8. menunjukan bahwa hasil uji multikolonieritas didapatkan dari nilai Tolerance value atau nilai VIF untuk word of mouth adalah 0,924>0,1 atau $1,083<10$. Nilai Tolerance value atau nilai VIF untuk kualitas jasa adalah 0,926 
$>0,1$ atau $1,080<10$. Nilai Tolerance value atau nilai VIF untuk harga adalah $0,974>0,1$ atau $1,027<10$.

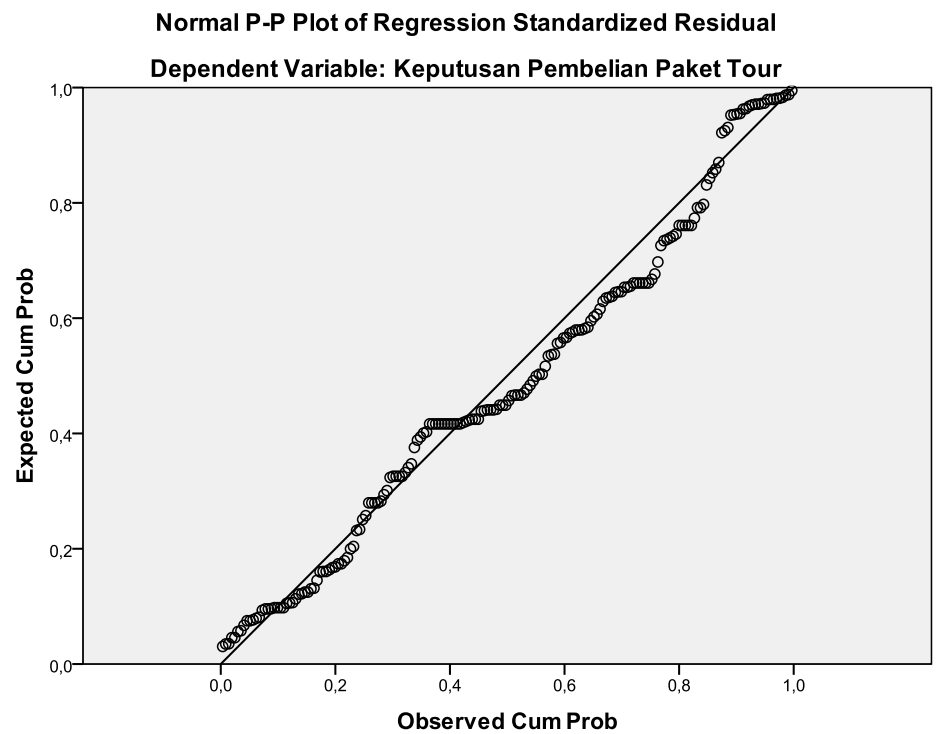

Gambar 3. Normal P-P Plot of Regression Standarized Residual

Sumber: Data primer yang diolah, 2020

Tabel 7.

Tabel Uji Normalitas

\begin{tabular}{|c|c|c|}
\hline & & $\begin{array}{l}\text { Unstandardized } \\
\text { Residual }\end{array}$ \\
\hline $\mathrm{N}$ & & 188 \\
\hline \multirow{2}{*}{ Normal Parameters ${ }^{\mathrm{a}, \mathrm{b}}$} & Mean & ,0000000 \\
\hline & Std. Deviation & ,47558366 \\
\hline \multirow[t]{3}{*}{ Most Extreme Differences } & Absolute &, 088 \\
\hline & Positive & 088 \\
\hline & Negative &,- 065 \\
\hline Kolmogorov-Smirnov Z & & 1,204 \\
\hline Asymp. Sig. (2-tailed) & &, 110 \\
\hline
\end{tabular}

Sumber: Data primer yang diolah, 2020

Tabel 8.

Tabel Uji Multikolonieritas

\begin{tabular}{clrr}
\hline Model & & \multicolumn{2}{c}{ Collinearity Statistics } \\
\cline { 3 - 4 } & & Tolerance & VIF \\
\hline \multirow{2}{*}{1} & WOM &, 924 & 1,083 \\
& Kualitas Jasa &, 926 & 1,080 \\
& &, 974 & 1,027 \\
& Harga & & \\
\hline
\end{tabular}

Sumber: Data primer yang diolah, 2020 


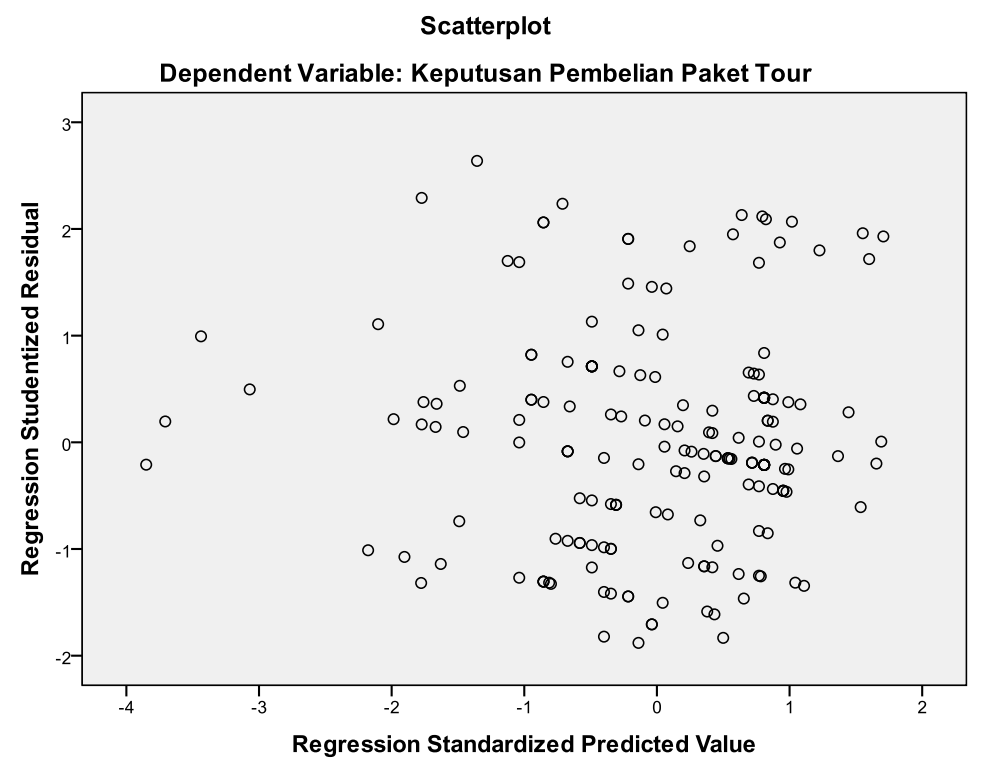

Gambar 4. Scatterplot

Sumber: Data primer yang diolah, 2020

Gambar 4. memperlihatkan grafik scatterplot yang titik-titiknya tidak tersebar dengan acak sehingga membentuk suatu pola tertentu dengan sangat jelas dan menyebar dengan sangat baik dibawah / diatas 0 sumbu Y.

Tabel 9.

Hasil Metode Glejser

\begin{tabular}{|c|c|c|c|c|c|c|}
\hline \multirow[b]{2}{*}{ Model } & & \multicolumn{2}{|c|}{ Unstandardized Coefficients } & \multirow{2}{*}{$\begin{array}{c}\text { Standardized } \\
\text { Coefficients }\end{array}$} & \multirow[b]{2}{*}{$\mathbf{t}$} & \multirow[b]{2}{*}{ Sig. } \\
\hline & & B & Std. Error & & & \\
\hline \multirow[t]{4}{*}{1} & (Constant) & -.209 & .950 & &,- 221 & 826 \\
\hline & WOM & -.186 & .094 &,- 149 & $-1,979$ & .059 \\
\hline & Kualitas Jasa & ,079 & ,054 & ,110 & 1,460 & , 146 \\
\hline & Harga & 265 & 211 & ,092 & 1,253 & ,212 \\
\hline
\end{tabular}

Sumber: Data primer yang diolah, 2020

Data diatas menunjukkan nilai signifikan WOM yaitu 0,059. Nilai uji signifikan kualitas jasa pada 0,146. Nilai uji signifikan harga pada 0,212.

Persamaan yang dapat dibuat dari kutipan data Tabel 10.

$\mathrm{Y}=7,311+0,034 \mathrm{WOM}+$ 0,099 Kualitas Jasa - 0,986 Harga

Koefisien-koefisien dalam persamaan berarti. Nilai Konstanta $=7,311$ satuan yang berarti variabel bebas yaitu WOM, kualitas jasa, dan harga bernilai 0, maka keputusan pembelian paket tour PT Bola Emas Sumatera Travel adalah tetap sebesar 7,311 satuan. Koefisien regresi WOM $\left(b_{1}\right)=0,034$ satuan. Hal ini menunjukkan setiap peningkatan satuan WOM akan menyebabkan kenaikan keputusan pembelian paket tour sebesar 0,034 satuan. Koefisien regresi kualitas 
jasa $\left(b_{2}\right)=0,099$ satuan. Hal ini menunjukkan setiap peningkatan satuan kualitas jasa menyebabkan kenaikan keputusan pembelian paket tour sebesar 0,099 satuan. Koefisien regresi harga $\left(b_{3}\right)=-0,986$ satuan. Hal ini menunjukkan setiap peningkatan satuan harga akan menyebabkan penurunan keputusan pembelian paket tour sebesar 0,986 satuan.

Tabel 10.

Tabel Analisis Regresi Linear Berganda

\begin{tabular}{|c|c|c|c|c|c|c|}
\hline \multirow[b]{2}{*}{ Model } & & \multicolumn{2}{|c|}{ Unstandardized Coefficients } & \multirow{2}{*}{$\begin{array}{c}\begin{array}{c}\text { Standardized } \\
\text { Coefficients }\end{array} \\
\text { Beta }\end{array}$} & \multirow[b]{2}{*}{$\mathbf{t}$} & \multirow[b]{2}{*}{ Sig. } \\
\hline & & B & Std. Error & & & \\
\hline \multirow[t]{4}{*}{1} & (Constant) & 7,311 & 1,539 & & 4,751 &, 000 \\
\hline & WOM & 034 &, 152 & 017 &, 221 &, 825 \\
\hline & Kualitas Jasa & ,099 & 087 &, 085 & 1,133 & 259 \\
\hline & Harga &,- 986 &, 342 &,- 210 & $-2,878$ &, 004 \\
\hline
\end{tabular}

Sumber: Data primer yang diolah, 2020

Tabel 11.

Tabel Koefisien Determinasi Hipotesis

\begin{tabular}{ccccc}
\hline Model & R & R Square & $\begin{array}{c}\text { Adjusted R } \\
\text { Square }\end{array}$ & $\begin{array}{c}\text { Std. Error } \\
\text { of the } \\
\text { Estimate }\end{array}$ \\
\hline 1 &, $222^{\mathrm{a}}$ &, 049 &, 034 &, 47945 \\
\hline
\end{tabular}

Sumber: Data primer yang diolah, 2020

Data diatas menunjukkan besarnya adjusted $\mathrm{R}$ Square yaitu 0,034. Disimpulkan adanya pengaruh WOM, kualitas jasa, dan harga terhadap keputusan pembelian paket tour PT Bola Emas Sumatera Travel sebesar 3,4\%. Sisanya sebesar $96,60 \%$ dipengaruhi variabel lain yang tak diteliti di penelitian ini seperti kepuasan pelanggan, persaingan bisnis, promosi, dan kualitas layanan.

Tabel 12.

Tabel Pengujian Hipotesis secara Simultan (uji-F)

\begin{tabular}{llrrrrr}
\multicolumn{7}{c}{ ANOVA $^{\mathbf{b}}$} \\
\multicolumn{1}{c}{ Model } & & Sum of Squares & df & Mean Square & \multicolumn{1}{c}{ F } & Sig. \\
\hline 1 & Regression & 2,201 & 3 &, 743 & 3,192 & $.025^{\text {a }}$ \\
& Residual & 42,296 & 184 &, 230 & & \\
& Total & 44,497 & 187 & & & \\
\hline
\end{tabular}

a. Predictors: (Constant), Harga, Kualitas Jasa, WOM

b. Dependent Variable: Keputusan Pembelian Paket Tour

Sumber: Data primer yang diolah, 2020

Tabel 11. menunjukkan nilai $F_{\text {hitung }}$ adalah 3,192 dengan tingkat

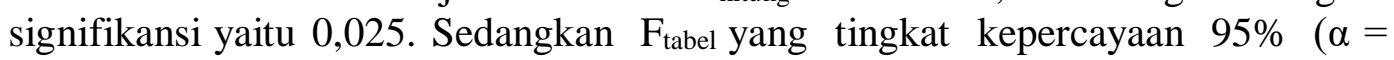
$0,05)$ yaitu 2,65, disebabkan oleh $F_{\text {hitung }}>F_{\text {tabel }}$ atau 3,192>2,65 dengan signifikan $0,025<0,05$ maka $\mathrm{H}_{\mathrm{a}}$ di terima dan $\mathrm{H}_{0}$ di tolak. Hal ini 
membuktikan WOM, kualitas jasa, dan harga mempunyai pengaruh secara signifikan dan simultan terhadap keputusan pembelian paket tour PT Bola Emas Sumatera Travel.

Tabel 13. Tabel Pengujian Hipotesis Secara Parsial (uji-t)

\begin{tabular}{|c|c|c|c|c|c|c|}
\hline \multirow[b]{2}{*}{ Model } & & \multicolumn{2}{|c|}{ Unstandardized Coefficients } & \multirow{2}{*}{$\begin{array}{c}\begin{array}{c}\text { Standardized } \\
\text { Coefficients }\end{array} \\
\text { Beta } \\
\end{array}$} & \multirow[b]{2}{*}{$\mathbf{t}$} & \multirow[b]{2}{*}{ Sig. } \\
\hline & & B & Std. Error & & & \\
\hline \multirow[t]{4}{*}{1} & (Constant) & 7,311 & 1,539 & & 4,751 &, 000 \\
\hline & WOM & ,034 & ,152 & ,017 & ,221 &, 825 \\
\hline & Kualitas Jasa & 099 & 087 & 085 & 1,133 & ,259 \\
\hline & Harga &,- 986 & ,342 &,- 210 & $-2,878$ &, 004 \\
\hline
\end{tabular}

Sumber: Data primer yang diolah, 2020

Variabel WOM mempunyai nilai signifikan 0,825 > 0,05 kemudian hasil $t_{\text {hitung }}<\mathrm{t}_{\text {tabel }}(0,221<1,97294)$ maka $\mathrm{H}_{0}$ di terima \& Ha di tolak. Hal ini berarti WOM tidak mempunyai pengaruh signifikan dan positif secara parsial terhadap keputusan pembelian paket tour PT Bola Emas Sumatera Travel.

Variabel kualitas jasa mempunyai nilai signifikan 0,259>0,05 kemudian hasil $t_{\text {hitung }}<\mathrm{t}_{\text {tabel }}(1,133<1,97294)$ maka $\mathrm{H}_{0}$ di terima \& Ha di tolak. Hal ini berarti bahwa kualitas jasa secara parsial tidak mempunyai pengaruh signifikan dan positif terhadap keputusan pembelian paket tour PT Bola Emas Sumatera Travel.

Variabel harga mempunyai nilai signifikan $0,004<0,05$ kemudian hasil $\mathrm{t}_{\text {hitung }}<\mathrm{t}_{\text {tabel }}(-2,878>1,97294)$ maka $\mathrm{H}_{0}$ di tolak \& Ha di terima. Hal ini berarti harga mempunyai pengaruh signifikan dan negatif secara parsial terhadap keputusan pembelian paket tour PT Bola Emas Sumatera Travel.

Hasil analisis regresi menunjukan secara parsial WOM tidak mempunyai pengaruh positif dan signifikan terhadap keputusan pembelian paket tour PT Bola Emas Sumatera Travel. Terlihat pada nilai thitung yang dibandingkan nilai tabel dan menghasilkan $t_{\text {hitung }}<t_{\text {tabel }}(0,221<1,97294)$ dan signifikansi diatas 0,05 $(0,825>0,05)$ sehingga hipotesis 1 tidak didukung. Hal ini mengindikasi pelaksanaan WOM yang diterapkan di PT Bola Emas Sumatera Travel masih kurang. WOM sebagai media terkuat dalam memasarkan suatu produk/jasa kepada satu ataupun sekelompok calon konsumen. WOM hadir secara alamia dan selalu bersifat kejujuran sehingga menjadi pesan berupa pemasaran paling efektif dibandingkan dengan media lainnya. Hasil penelitian ini tak sependapat dengan penelitian Pamungkas (2016). Hasilnya berupa promosi yang dilakukan dimedia sosial (Medsos) merupakan strategi dari pemasaran yang sangat cukup inovatif \& efektif dan tentunya dengan dukungan WOM yang masih baik bisa memicu perhatian konsumen untuk bertransaksi. Hal ini terjadi karena word of mouth masih kurang karena masyarakat kurang mengetahui PT Bola Emas Sumatera Travel. Kurangnya melakukan promosi terhadap penawaran yang diberikan membuat perusahaan kurang dikenal di masyarakat. Salah satu faktor 
penting lainnya adalah kurang aktifnya perusahaan dalam media digitalisasi seperti whatapps, instagram dan facebook.

Hasil analisis regresi menunjukan kualitas jasa tidak mempunyai pengaruh positif dan secara parsial signifikan terhadap keputusan pembelian paket tour PT Bola Emas Sumatera Travel. Terlihat pada nilai thitung yang dibanding nilai $t_{\text {tabel }}$ dan menghasilkan $t_{\text {hitung }}<\mathrm{t}_{\text {tabel }}(1,133<1,97294)$ dan signifikansi diatas 0,05 $(0,259>0,05)$ sehingga hipotesis 2 tidak didukung. Hal ini mengindikasi kualitas jasa yang diutarakan oleh staf PT Bola Emas Sumatera masih kurang kepada konsumen. Apabila kualitas layanan yang diperoleh dan rasakan cocok sesuai yang dipersepsikan, maka kualitas jasa akan mendapatkan nilai baik dan puas. Kepuasan terbentuk agar dapat memicu konsumen melakukan repeat-order dan berstatus pelanggan setia perusahaan. Hasil penelitian tidak sependapat dengan penelitian Pamungkas (2016), Lubis (2017), dan Manengal (2015). Hasil penelitiannya yaitu kualitas jasa yang diberikan oleh staf PT Bola Emas Sumatera masih kurang kepada konsumen. Untuk meningkatkan kualitas layanan dengan cara memberikan training karyawan mengenai cara menghadapi komplain.

Hasil analisis regresi menunjukkan harga mempunyai pengaruh negatif dan secara parsial signifikan terhadap keputusan pembelian paket tour PT Bola Emas Sumatera Travel. Terlihat dari nilai $t_{\text {hitung }}$ yang dibandingkan dengan nilai $t_{\text {tabel }}$ dan menghasilkan $t_{\text {hitung }}<t_{\text {tabel }}(2,878<1,97294)$ dan signifikansi dibawah $0,05(0,004$ $<0,05)$ sehingga hipotesis 3 didukung. Hal ini mengindikasi harga yang diberikan oleh staf PT Bola Emas Sumatera relatif murah. Penentuan harga bertujuan untuk mendatangkan profit. Harga yang diberikan oleh staf PT Bola Emas Sumatera relatif murah. Masyarakat kota Medan rata-rata sudah mengetahui bahwa PT Bola Emas Sumatera Travel memberikan harga yang dapat bersaing di pasaran dikarenakan perusahaan sudah berdiri puluhan tahun dan selalu memegang teguh prinsip harga yang terjangkau sehingga menarik minat pelanggan baik di kota Medan maupun kota lainnya. Hasil penelitian sependapat dengan penelitiannya Lubis (2017) dan Manengal (2015). Hasil penelitiannya menunjukkan harga yang diberikan oleh staf PT Bola Emas Sumatera relatif murah sehingga konsumen membeli paket tour.

Hasil analisis regresi menunjukkan WOM, kualitas jasa, dan harga mempunyai pengaruh positif dan secara simultan signifikan terhadap keputusan pembelian paket tour PT Bola Emas Sumatera Travel. Hal ini terlihat pada F $F_{\text {hitung }}$ $>F_{\text {tabel }}$ atau 3,192 > 2,65 dengan signifikan 0,025 < 0,05 sehingga hipotesis 4 didukung. Secara bersamaan WOM, kualitas jasa, dan harga mempunyai pengaruh terhadap keputusan pada pembelian paket tour PT Bola Emas Sumatera Travel. Jika dalam perusahaan ketiga variabel tersebut berjalan dengan maksimal, maka dinilai akan meningkatkan kestabilan keputusan pada pembelian.

Hasil dari uji koefisien determinasi adalah besarnya adjusted $\mathrm{R}$ Square adalah 0,034, maka pengaruh WOM, kualitas jasa, dan harga terhadap keputusan pembelian paket tour PT Bola Emas Sumatera Travel adalah 3,4\%. Sisanya yaitu $96,60 \%$ dipengaruhi variabel lain yang tak diteliti di penelitian ini antara lain seperti kepuasan pelanggan, persaingan bisnis, promosi, dan kualitas layanan. 


\section{SIMPULAN}

Hasil penelitian terbukti bahwa WOM dan kualitas jasa tidak mempunyai pengaruh secara parsial yang positif terhadap keputusan pembelian paket tour PT Bola Emas Sumatera Travel. Harga memiliki pengaruh negatif secara parsial terhadap keputusan pembelian paket tour PT Bola Emas Sumatera Travel. WOM, kualitas jasa, dan harga secara simultan berpengaruh terhadap keputusan pembelian paket tour PT Bola Emas Sumatera Travel. Pelanggan yang umurnya paling dominan melakukan pembelian paket tour adalah yang berusia sekitar 4150 tahun yang merupakan kalangan orang tua dengan tujuan untuk menghabiskan waktu luang dan juga diperlukan dana yang cukup besar untuk melakukan transaksi paket tour. Pelanggan yang tingkat pendidikannya paling dominan melakukan pembelian paket tour adalah tingkat pendidikan jenjang S1 yang umumnya dari kalangan pebisnis. Pelanggan yang jenis kelaminnya paling dominan melakukan pembelian paket tour adalah yang jenis kelamin laki-laki. Diketahui bahwa jumlah pelanggan perempuan yang memesan paket tour hampir sama dengan laki-laki. Pelanggan yang frekuensi pembelian dalam 1 tahun paling dominan melakukan pembelian paket tour yaitu antara 1-5x dikarenakan pelanggan tidak selalu menggunakan jasa PT Bola Emas Sumatera Travel setiap liburan.

Saran yang dapat diberikan oleh peneliti bagi PT Bola Emas Sumatera Travel sebagai bahan masukan bagi perusahaan yaitu word of mouth dan kualitas jasa harus diperbaiki dimasa-masa yang akan datang dan tetap konsisten dalam menetapkan harga yang terjangkau. Jika ingin mencapai target penjualan, disarankan perusahaan harus sering memanfaatkan media sosial agar masyarakat dapat mengetahui penawaran apa saja yang diberikan. Teruntuk peneliti selanjutnya, disarankan mengubah variabel penelitian menjadi yang mempengaruhi keputusan pembelian antara lain seperti kepuasan pelanggan atau promosi. Hasil penelitian bisa dipertimbangkan untuk dikembangkan dengan metode SEM. Peneliti selanjutnya juga dapat meneliti objek penelitian yang bergerak dibidang manufaktur.

\section{REFERENSI}

Abdurahhman, N. H. (2015). Manajemen Strategi Pemasaran. Bandung: CV Pustaka Setia.

Alma, B. H. (2018). Manajemen Pemasaran \& Pemasaran Jasa. Bandung: Alfabeta.

Assauri, S. (2014). Manajemen Produksi \& Operasi. Jakarta: LPFEUI.

Damiati. (2017). Perilaku Konsumen. Jakarta: PT Rajagrafindo Persada.

Ginting, N. F., \& Hartimbul. (2017). Manajemen.Pemasaran. Bandung: CV Yrama Widya. 
Kotler, P., \& Gary Amstrong. (2018). Prinsip-prinsip.Pemasaran 1. Edisi Keduabelas. Jakarta: Erlangga.

Kotler, P., \& Ketler. (2009). Manajemen Pemasaran 2 Edisi Keduabelas. Jakarta: Erlangga.

Limakrisna, N., \& Susilo, W. H. (2012). Manajemen Pemasaran: Teori \& Aplikasi Dalam Bisnis. Jakarta: Mitra Wacana Media.

Lubis, R. K. (2017). Pengaruh Kualitas.Layanan, Harga Terhadap Keputusan Pembelian Paket Tour PT.Dior Travel Lubuk Pakam. Jurnal Mantik Penusa, l(1).

Malau, H. (2016). Manajemen.Pemasaran: Teori \& Aplikasi Pemasaran Era Tradisional.Sampai Era Moderniasasi Global. Bandung: Alfabeta.

Manengal, C. D. (2015). referensiPengaruh.Kualitas Layanan, Kualitas Produk \& Penetapan Harga Terhadap.Keputusan Pembelian pada CV Esa Genangku (Esacom) Manado. Jurnal.EMBA, 3(3).

Pamungkas, B. A. (2016). Pengaruh.Promosi Di Media Sosial \& Word Of Mouth Terhadap Keputusan.Pembelian (Studi Kasus Pada Kedai Bontacos, Jombang). Jurnal.Komunikasi, 10(2).

Rusdiana, A. (2014). Manajemen.Operasi. Bandung: CV Pustaka Setia.

Sangadji, E., Mamang, \& Sopiah. (2013). Perilaku Konsumen: Pendekatan Praktis Disertai.Himpunan Jurnal Penelitian. Yogyakarta: Andi.

Shimp, T. A. (2014). Komunikasi.Pemasaran Terpadu.dalam periklanan \& Promosi. Jakarta: Salemba Empat.

Sugiyono. (2017). Metode Penelitian Bisnis (Pendekatan Kuantitatif, Kualitatif, Kombinasi dan R\&DSugiyono. (2017). Metode Penelitian Bisnis (Pendekatan Kuantitatif, Kualitatif, Kombinasi dan R\&D). In Metodelogi Penelitian.). In Metodelogi Penelitian.

Sunyoto, D. (2014). Dasar-Dasar Manajemen Pemasaran. Yogyakarta: CAPS.

Sutisna. (2012). Perilaku Konsumen \& Komunikasi Pemasaran. Bandung: Remaja Rosdakarya. 
E-Jurnal Manajemen, Vol. 9, No. 8, $2020: 3193-3213$

Tjiptono, F. (2012). Manajemen Pemasaran Jasa. Yogyakarta: Andi.

Tjiptono, F., \& Diana, A. (2016). Pemasaran: Esensi \& Aplikasi. Yogyakarta: Andi.

Wibowo. (2016). Manajemen Kinerja. Jakarta: PT Rajagrafindo Persada.

Wibowo, L. A., \& Donni, J. P. (2017). Manajemen Komunikasi \& Pemasaran. Bandung.: Alfabeta. 